\title{
Optimising Aerosol Delivery for Maxillary Sinus Deposition in a Post-FESS Sinonasal Cavities
}

Aerosol and Air Quality Research

\section{OPEN ACCESS}

Received: April 25, 2021

Revised: July 16, 2021

Accepted: September 11, 2021

\section{${ }^{*}$ Corresponding Author:}

kiao.inthavong@rmit.edu.au

Publisher:

Taiwan Association for Aerosol Research

ISSN: $1680-8584$ print ISSN: 2071-1409 online

(c) Copyright: The Author(s). This is an open access article distributed under the terms of the Creative Commons Attribution License (CC BY 4.0), which permits unrestricted use, distribution, and reproduction in any medium, provided the original author and source are cited.

\section{Sara Vahaji ${ }^{1}$, Yidan Shang ${ }^{2}$, Yu Zhang ${ }^{2}$, Eugene Wong ${ }^{3,4}$, Amgad Rezk ${ }^{5}$, Leslie $\mathrm{Yeo}^{5}$, Sarah Vreugde ${ }^{6}$, Peter-John Wormald ${ }^{6}$, Narinder Singh ${ }^{4}$, Kiao Inthavong ${ }^{2 *}$}

\author{
${ }^{1}$ School of Engineering, Deakin University,Geelong, Victoria 3217, Australia \\ ${ }^{2}$ Mechanical and Automotive Engineering, School of Engineering, RMIT University, Bundoora, \\ Victoria 3083, Australia \\ ${ }^{3}$ Department of Otolaryngology, Head and Neck Surgery, Westmead Hospital, Sydney, Australia \\ ${ }^{4}$ Westmead Clinical School, Faculty of Medicine and Health, The University of Sydney, \\ Westmead Hospital, Sydney, NSW, Australia \\ ${ }^{5}$ Chemical Engineering, School of Engineering, RMIT University, Melbourne, Victoria 3000, \\ Australia \\ ${ }^{6}$ Department of Otolaryngology, Head and Neck Surgery, Adelaide Medical School, Australia
}

\section{ABSTRACT}

Optimal management of chronic rhinosinusitis (CRS) endotypes includes post-operative application of topical formulations. There is little evidence regarding the ideal aerosol delivery characteristics and techniques to achieve the most efficient deposition on affected sinus mucosa. Nebulisers provide an alternative to nasal sprays by producing smaller particle sizes at lower velocities. We applied a reverse-particle-tracking simulation using computational fluid dynamics (CFD) to evaluate the ideal aerosol characteristics from a nebuliser to target the post-operative maxillary sinus mucosa. A CT scan of a CRS patient was used to create a pre-operative and virtual post-operative model. Particles of diameter 2 to $30 \mu \mathrm{m}$ were tracked through the sinonasal cavity at 5, 10 and $15 \mathrm{~L} \mathrm{~min}^{-1}$ flow rates using CFD. Reverse particle simulations demonstrated that the optimised combination of parameters were $20 \mu \mathrm{m}$ particles, delivered at $5 \mathrm{~m} \mathrm{~s}^{-1}$ (or 14 microns, delivered at $15 \mathrm{~m} \mathrm{~s}^{-1}$ ) at an inhalation rate of $5 \mathrm{~L} \mathrm{~min}^{-1}$, released from a nozzle in an elliptical oblique-superior direction into the superior half of the nasal valve significantly improved the maximum deposition efficiency (from $3 \%$ up to $55 \%$ ) in the post-operative maxillary sinus mucosa. The nebulised spray (without optimisation) demonstrated negligible particle deposition within the sinuses of the pre-op model, while it increased marginally in the post-op model for smaller diameter particles at lower inhalation rates. The ideal combination of parameters to achieve targeted medication deposition on specific sinus mucosal surfaces can guide the development of new nasal drug delivery devices that produce the desired deposition regions for clinical applications in post-operative CRS patients.

Keywords: Sinonasal cavity, Spray atomisation, Aerosol deposition, Inhaled aerosol, CFD

\section{INTRODUCTION}

Chronic rhinosinusitis (CRS) is a constellation of heterogeneous conditions, including various phenotypes and endotypes, causing disordered and excessive inflammation of the sinonasal mucosa, resulting in symptoms such as facial pain, nasal congestion, and nasal discharge. Treatment paradigms for CRS include topical corticosteroids (Luk and DelGaudio, 2017). However, the ideal delivery vehicle and method has not been established. The current literature examining the efficacy of nasal sprays of corticosteroids have yielded inconsistent results, largely due to the variability in the ability of sprays to reach the affected mucosa (Saijo et al., 2004; Kimbell et al., 2007; 
Snidvongs et al., 2013; Djupesland et al., 2019; Siu et al., 2019).

The complex nasal cavity geometry creates an enormous challenge for targeted drug delivery, with specific anatomical projections at the nasal valve, turbinates and sinus ostia impeding spray distribution. This is similar to the upper respiratory airway that is exposed to aerosols (Mutuku et al., 2020; Chen et al., 2021) during breathing. Additionally, in the diseased sinonasal cavity, obstruction can occur secondary to pathological causes such as the presence of nasal polyps, septal deviation and obstruction of the ostiomeatal complex. The nature and properties of nasal sprays themselves create further obstacles to effective topical medication distribution.

Nasal sprays typically deliver particles with a mean aerodynamic diameter size of $50 \mu \mathrm{m}$ travelling at initial velocities of 15-20 $\mathrm{m} \mathrm{s}^{-1}$ (Kimbell et al., 2007; Fung et al., 2013; Siu et al., 2020), producing high inertia properties. This leads to spray deposition by inertial impaction onto the anterior nasal cavity (Cheng et al., 2001; Djupesland and Skretting, 2012; Lam et al., 2013), thereby failing to navigate through the narrowed passages and reach the affected sinus mucosa. To improve medication delivery to the paranasal sinuses, alternative delivery mechanisms have been suggested, such as pulsed nebulisation (Winfried et al., 2014), and bidirectional flow applicators (Djupesland et al., 2004) that can be tuned to produce aerosol conditions that are more conducive for targeted sinus delivery.

A parametric study applying different combinations of aerosol delivery can be performed efficiently using Computational Fluid Dynamics (CFD), by modelling air and particle flow through the sinonasal tract. The technique has provided reproducible and detailed data leading to clinically relevant outcomes (Lee et al., 2016; Sanmiguel-Rojas et al., 2018; Inthavong, 2020). CFD simulations have offered detailed insight into the cause of sprayed particle deposition in the anterior nasal cavity due to high particle inertia (Chen et al., 2010; Inthavong et al., 2011; Frank et al., 2012).

Studies of inhalation exposure have used a 'reverse-simulation technique' that tracked indoor airborne particles to locate their release sources (Kleinstreuer et al., 2008; Zhang et al., 2012) and similarly particles that deposited in the lungs were traced back to their original source locations (Inthavong et al., 2012, 2013). This technique was later applied in Dong et al. (2018) who identified the optimal release locations of inhaled drug particles to target olfactory deposition.

This study is aimed at using the 'reverse-simulation technique' to identify the optimal particle size, and initial release locations in the nasal vestibule that enhances maxillary sinus deposition. This proof-of-concept study is expected to facilitate further studies examining the efficacy of drug delivery devices in multiple patient models with various anatomical and physiological features. We characterised the spray produced from a mesh nebuliser to provide a range of realistic values for the initial particle conditions as an alternative to nasal sprays. The nasal valve region is the most constrictive cross-sectional area of the nasal cavity. It is hypothesised that by narrowing the spray plume, improved drug delivery efficacy could be achieved to penetrate the nasal valve region. Furthermore, spray deposition variations are expected from different inhalation flow rates, particle size and velocity, nozzle angle and patient-specific anatomy.

\section{MATERIALS AND METHODS}

\subsection{Nebuliser Spray Characterisation}

An ultrasonic vibrating mesh nebuliser $\left(\right.$ Tekceleo $^{\circledR}$ at $1 \mathrm{Mhz}, 3 \mathrm{~W}$ power input, response time of $1 \mathrm{~ms}$ ) was used to deliver a saline solution commonly used in nasal irrigation therapy. The aerosol head contained a mesh size targeting particles of $12 \mu \mathrm{m}$ and a flow rate of $3 \mathrm{~mL} \mathrm{~min}{ }^{-1}$. The aerosol head was fitted with a custom-made nostril adapter piece that could be optimised for targeted spray plume geometries to direct the nebulised particles into the nasal cavity. High-speed imaging using the experimental test station diagram shown in Fig. 1 was used to characterise the spray plume and approximate particle velocities. A dark-field illumination method was used by illuminating the nebulised particles from the same direction as the camera. A black image background was created by providing sufficient space behind the particles, and lighting targeting the aerosol is contrasted in white. The high-speed imaging was performed with a field of view of approximately $33 \mathrm{~mm} \times 24 \mathrm{~mm}$, at a frame rate of 10,000 frames per second.

For particle size distributions, a Malvern Spraytec ${ }^{\circledR}$ laser diffraction system and the accompanying Spraytec 3.20 software was used for analysis. Since laser diffraction is a point measurement, the 


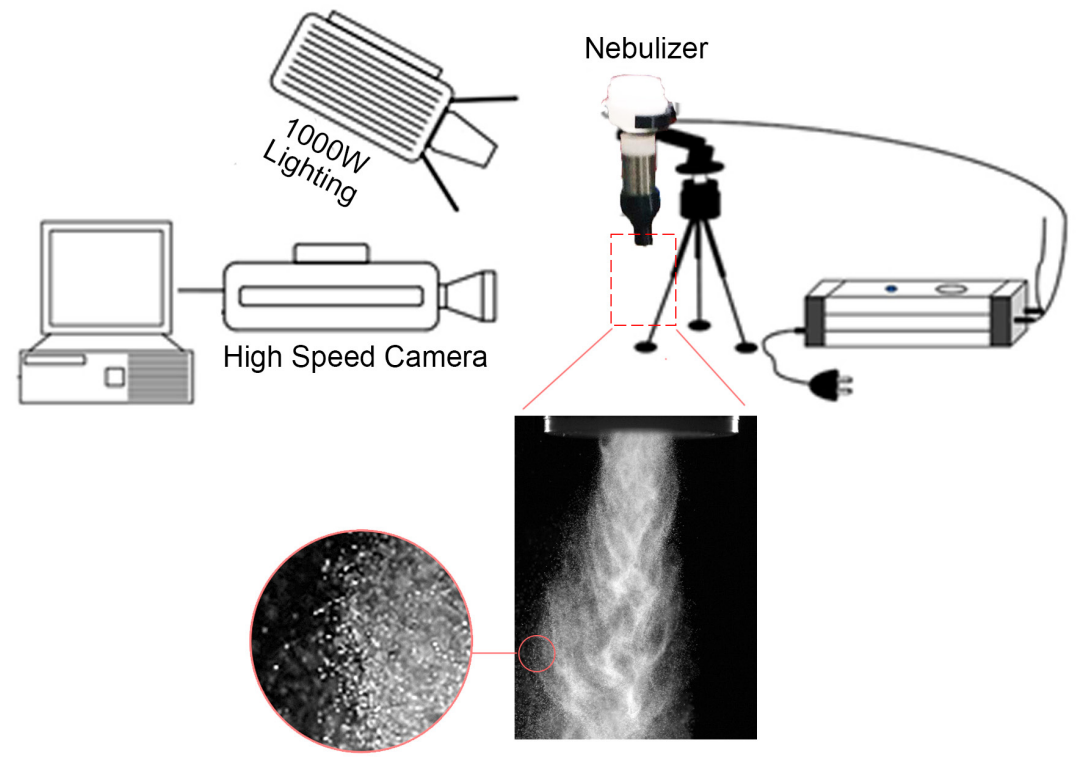

Fig. 1. High speed imaging setup demonstrating the nebuliser and a sample image taken at 10,000 frames per second. A zoomed view of the nebulised spray is shown.

measured data was taken at $15 \mathrm{~mm}$ from the nozzle tip (following Dayal et al. (2004)) and sampled for a minimum of 5 seconds at a rate of 1 sample per second, repeated three times.

\subsection{Nasal Geometry Reconstruction}

A CT scan was performed on a 75-year-old male with a confirmed diagnosis of CRS. The scan was performed on a Philips 128 slice Ingenuity machine taking $64 \times 0.625 \mathrm{~mm}$ slices in the supine position. Written informed consent was obtained from the patient and the Central Adelaide Health Ethics Committee. The scanned images were imported into 3D Slicer (Fedorov et al., 2012) where the nasal airway was determined and exported as the 'Pre-Op' model in stereolithography (STL) file format ready for computational modelling. In 3D Slicer, virtual surgery was performed by removing the regions typically addressed in real-life surgery by trained clinicians. Virtual surgery was used to avoid ethical concerns associated with radiation exposure from a clinically unnecessary post-op CT scan. Virtual surgery allowed the pre- and post-op models to be identical in all respects, other than the virtual surgery performed, and was performed by a trained clinician with expertise in anatomy and surgery. The surgical interventions performed incorporated bilateral radical antrostomy of the maxillary sinus, complete anterior and posterior ethmoidectomies, wide sphenoidotomies and Draf 2a frontal sinusotomy, which was prescribed for the patient. Regions of excessive mucosal thickening, such as maxillary sinus mucous retention cysts, were excised, as would be routinely performed during sinus surgery.

Fig. 2 shows a geometry comparison of the pre-operative (blue) paranasal sinuses (blue) and post-operative (red) models, with both 3D reconstructions and coronal slices shown. Regions of the sinonasal cavity incorporated into each model included the nostrils, nasal cavity, paranasal sinuses, nasopharynx and outer face.

The commercial software ANSYS-Fluent $\AA$-ver19.2 was used to create a computational polyhedral mesh with five prism layers applied in near-wall regions. The advantage of poly-hexcore meshing is that it uses fewer elements, approximate $3.5 \times$ fewer than tetrahedral meshing (with the same size functions) while achieving negligibly different results. The mesh strategy was based on a size functions evaluated in an earlier study in Inthavong et al. (2018) which found that a minimum scoped mesh cell size of $0.45 \mathrm{~mm}$ in the nasal cavity region but a much larger, coarse mesh in the outer ambient air region was optimal. A mesh independence test was performed on polyhedral meshes of $0.8 \mathrm{mil}, 1.47 \mathrm{mil}$, and $2.6 \mathrm{mil}$ by comparing the laminar velocity magnitude in coronal planes resulting in an optimised mesh of 1.47 million polyhedral and prism cells (7.4 mil faces, and equivalent to 3.8 million tetrahedral cells, see Supplementary Material). A schematic of the pre-op model and the computational mesh is shown in Fig. 3. 


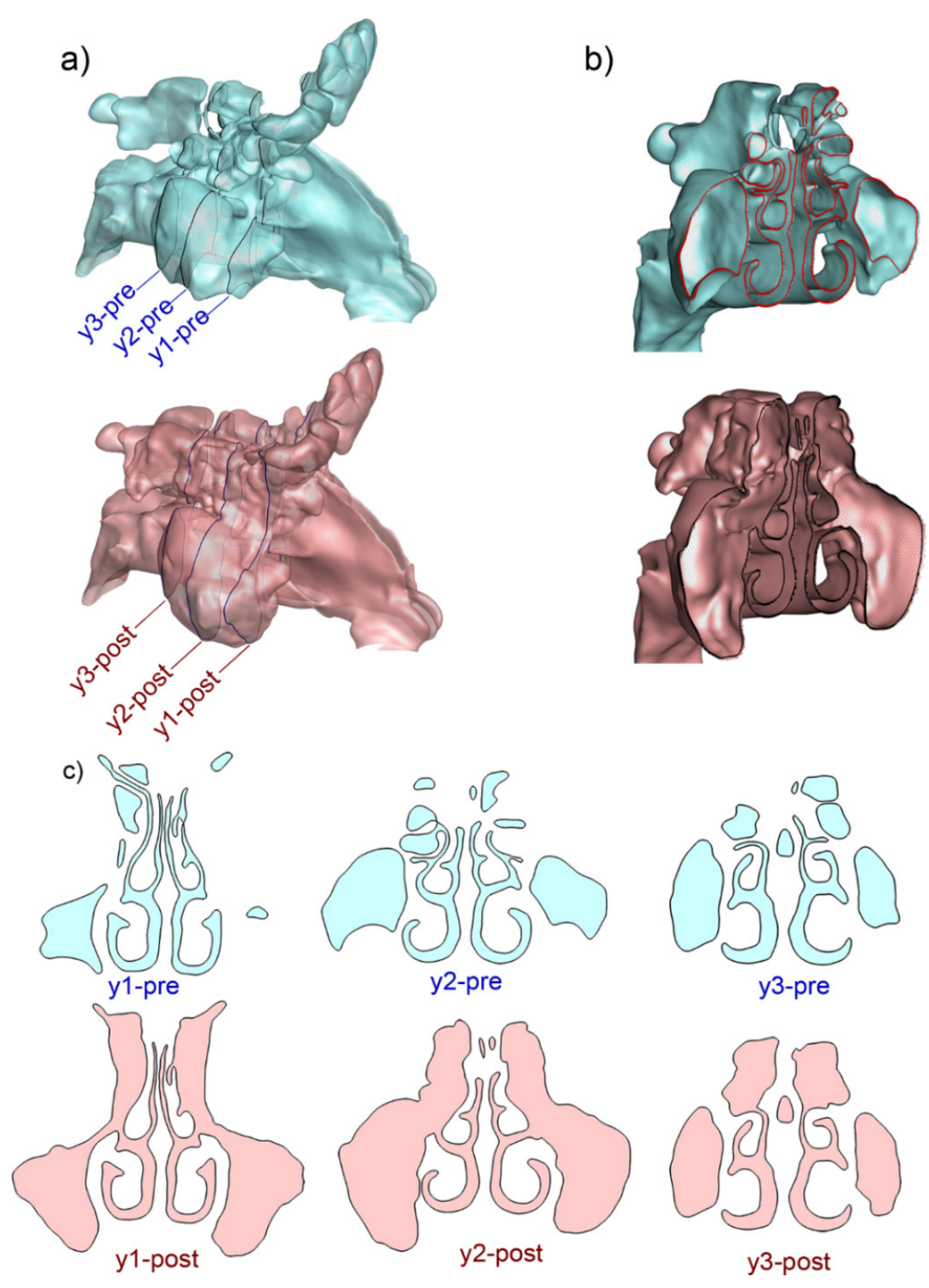

Fig. 2. Nasal geometry models extracted from CT scans using 3D-Slicer of a Pre-Op and Post-Op model. (a) Oblique 3D view of pre-op (blue) and post-op (red) models (right side is anterior), showing location of coronal slices. (b) Oblique 3D cut view of models showing coronal slices taken at level y2. (c) Coronal slices taken at identical levels, as indicated in 3D models in (a).

\subsection{Fluid-particle Simulation}

Three steady flow rates were used $\left(5,10\right.$, and $\left.15 \mathrm{~L} \mathrm{~min}^{-1}\right)$, with a laminar, incompressible flow model. The $15 \mathrm{~L} \mathrm{~min}^{-1}$ flow rate is representative of tidal breathing in adults (Chung, 2006), while the lower flow rates were used to determine if steady, shallow breathing could assist in reducing particle inertia, slowing down the drug particles delivered into the nasal cavity. The Lagrangian method to track individual particle trajectories was used. In this method, the airflow field was simulated first, and then the trajectories of individual particles were determined by integrating the particle force balance equation, accounting for the drag and gravity forces. The motion of particles with the gravity and drag force in Cartesian coordinates was given as:

$$
\frac{d u_{i}^{p}}{d t}=\frac{\left(u_{i}^{g}-u_{i}^{p}\right)}{\tau_{r}}+g_{i}\left(1-\frac{\rho^{g}}{\rho^{p}}\right)
$$

where $u_{i}^{g}$ is the fluid velocity, $u_{i}^{p}$ is the particle velocity, $\rho^{g}$ is the fluid density, $\rho^{p}$ is the density 


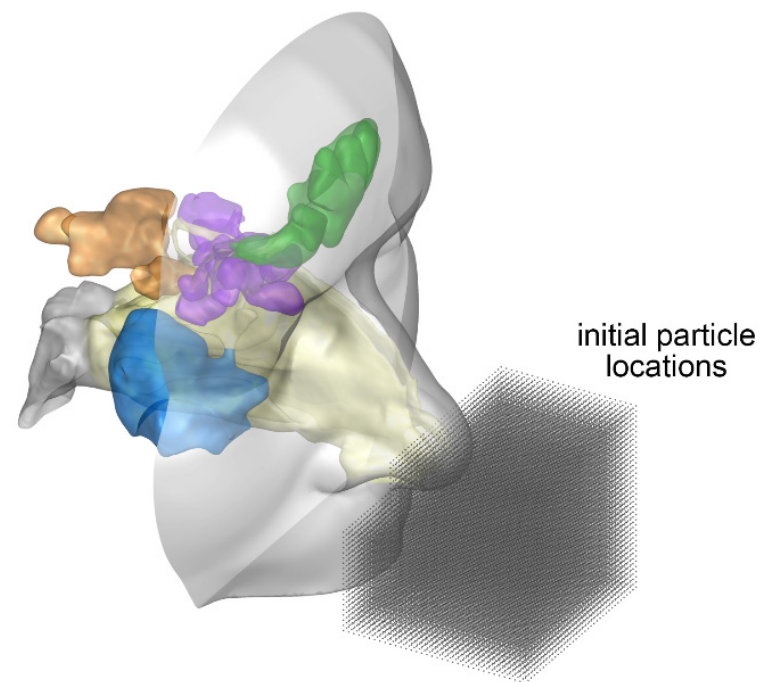

(a) 3D geometry with initial particle locations

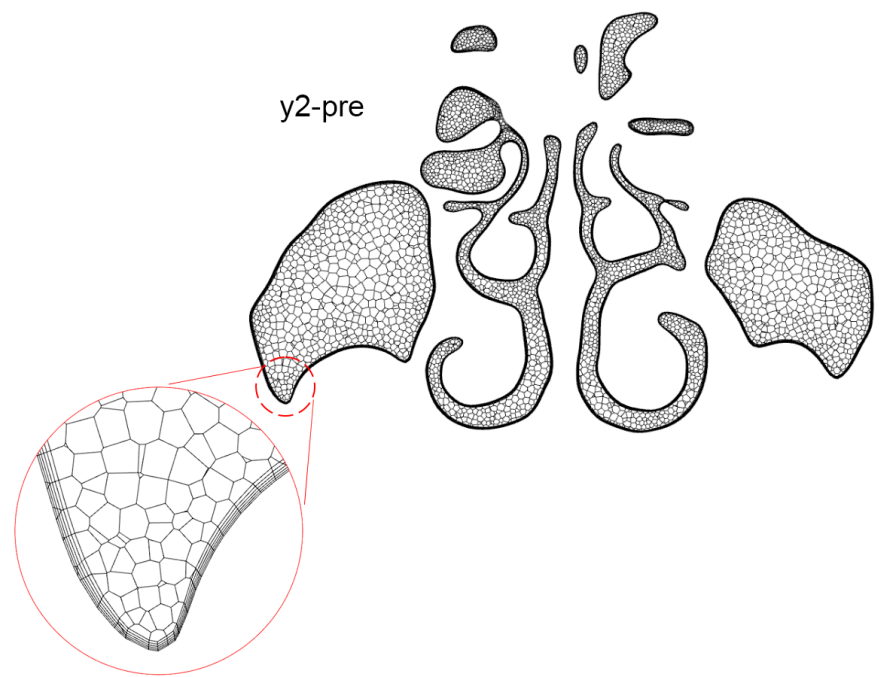

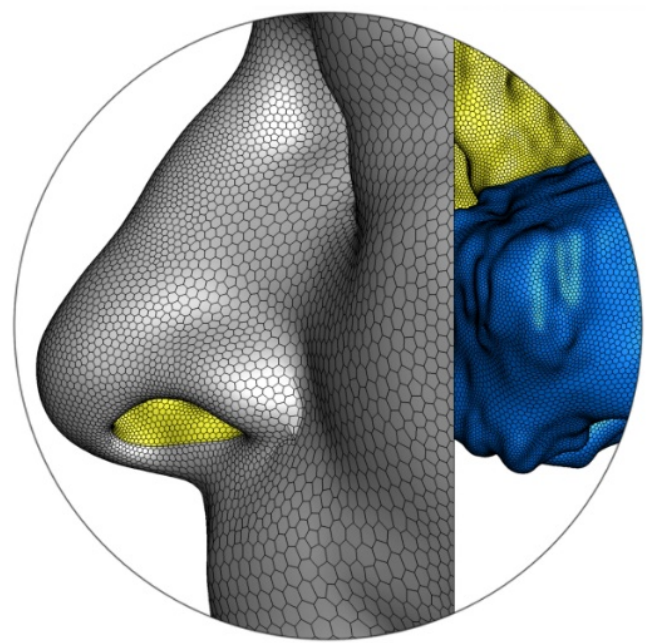

(b) Zoomed view of the polyhedral surface mesh

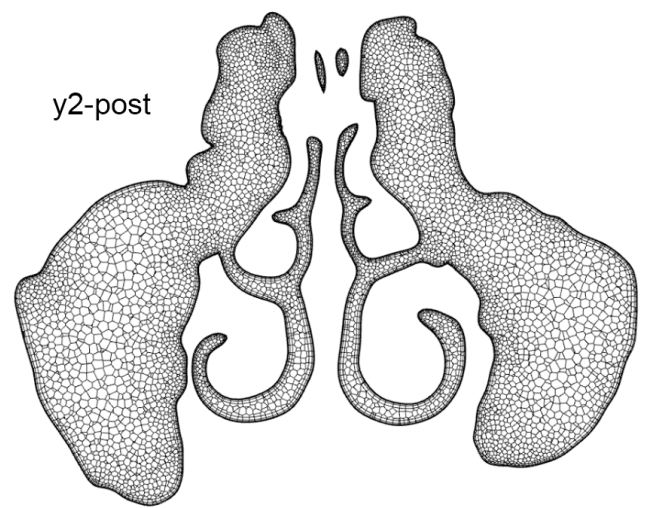

(c) Internal polyhedral mesh for the coronal slice y2

Fig. 3. (a) Geometry of the pre-op sino-nasal airway. (b) Zoomed view of the polyhedral mesh elements used for the simulations. Surfaces coloured by region - frontal sinus (Green); maxillary sinus (Blue); sphenoid sinus (Orange); nasal cavity (Yellow) and ethmoid sinuses (Purple). The rectangular dots outside the nose were the initial particle locations for particle uptake influenced by inhalation flow rates. (c) Internal volume mesh using polyhedral elements and five prism layers taken at the coronal slice y 2 for the pre-op and post-op models.

of the particle, $\frac{\left(u_{i}^{g}-u_{i}^{p}\right)}{\tau_{r}}$ is the drag force per unit mass of particle, $\tau_{r}$ is the particle relaxation time, calculated by

$$
\tau_{r}=\frac{\rho^{p} d_{p}^{2}}{18 \mu} \frac{24}{C_{D} \operatorname{Re}}
$$

where $\mu$ is the molecular viscosity of the fluid, $d_{p}$ is the particle diameter, and $\mathrm{Re}$ is the relative Reynolds number, which defines as

$$
\operatorname{Re}=\frac{\rho^{g} d_{p}\left|u^{p}-u^{g}\right|}{u}
$$


The drag force $F_{D}$ is dependent on the drag coefficient $C_{D}$, which was defined in Morsi and Alexander (1972)'s work:

$$
C_{D}=\frac{F_{D}}{\frac{1}{2} \rho^{g}\left(u^{g}-u^{p}\right)^{2} A}=a_{1}+\frac{a_{2}}{\operatorname{Re}}+\frac{a_{3}}{\operatorname{Re}^{2}}
$$

where $a_{1}, a_{2}$ and $a_{3}$ are empirical constants for smooth spherical particles.

The simulations involved tracking 60,000 particle streams of a single particle diameter just outside the nose (depicted in Fig 3(a)) so that the particles were naturally inhaled under the influence of the inhalation flow rates. This was repeated for every even-numbered particle diameter in a range $(2-30 \mu \mathrm{m})$ determined by the particle size distributions found from the nebuliser measurements (reported in the Results section). Thus, a total of 15 mono-dispersed particle diameter simulations of 60,000 individual particle streams were released from outside the face, and its deposition location was recorded (i.e., 900,000 particle streams). By reverse tracking the particles from the final deposition location, clusters of regionally deposited particles were identified for any location within the nasal cavity along their trajectory. This suggests that targeted drug delivery could be achieved by introducing particles to specific regions of the nostril that lead to the targeted deposition region, e.g., in this case, the paranasal sinuses.

\section{RESULTS}

\subsection{Nebulised Spray Characterisation Deposition}

The particle size distribution is shown in Fig. 4 where the particle diameters ranged between 1 to approximately $30 \mu \mathrm{m}$. Although particles larger than $30 \mu \mathrm{m}$ influence the volume by percentage, it's particle number count contributed very little to the overall number of particles. The size distribution was evaluated for the nebuliser with and without the nasal adapter nozzle piece attached shown in Fig. 4(a). When the adapter nozzle was attached, there was a slight decrease in the larger diameters and an increase in the smaller diameter sizes. High-speed imaging captured the spray, and the velocity was determined. The nozzle diameter was a known quantity along and the distance travelled by a fluid particle per pixel was estimated through image processing by using Python OpenCV. This, in combination with the time per frame, was used to overlay a cross-hair on the video footage at a given 'velocity' using a Python script. A trial and error method was used to find the cross-hair velocity that matched the flow of the droplets. This manual visual approach was checked against Trackpy (Python Particle-Tracking Toolkit), which gave similar results of the averaged velocity of $\sim 5 \mathrm{~m} \mathrm{~s}^{-1}$.

\subsection{Inhaled Particle Deposition}

Particle deposition was subdivided into three distinct regions; nasal cavity, sinuses (inclusive of all frontal, sphenoid, maxillary), and nasopharynx. Sinus and nasal cavity regions were further divided into left and right. In contrast, the nasopharynx was considered as a single region. Particles that passed through the nasopharyngeal outlet into the lower airway without depositing on any walls were considered not-deposited. The deposition efficiency per particle diameter was calculated as the sum of the particle deposit in a region (per diameter) divided by the number of particles inhaled (per diameter). Fig. 5 shows the deposition efficiency in each of the three areas for all three inhalation flow rates, which includes the effects of surgery on deposition by the 'net-change' deposition plot. Higher inhalation flow rates increased total deposition. Larger particle sizes increased total deposition and resulted in fewer particles passing through the nasopharyngeal outlet.

There was negligible deposition in the sinuses $(<0.1 \%)$ in the Pre-Op model for all flow rates. At the lowest flow rate, $5 \mathrm{~L} \mathrm{~min}^{-1}$, the total deposition efficiency gradually increased from $2 \%$ for $2 \mu \mathrm{m}$ particles to $70 \%$ for $30 \mu \mathrm{m}$ particles. At $10 \mathrm{~L} \mathrm{~min}^{-1}$, a big increase in deposition was found between $20 \mu \mathrm{m}$ to $22 \mu \mathrm{m}$ particles, while for $15 \mathrm{~L} \mathrm{~min}^{-1}$, this occurred between $14 \mu \mathrm{m}$ and $18 \mu \mathrm{m}$ particles. More deposition was found in the left chamber than the right for particles smaller than $14 \mu \mathrm{m}$ for all flow rates due to different sizes of asymmetric airway volumes during nasal cycling. 


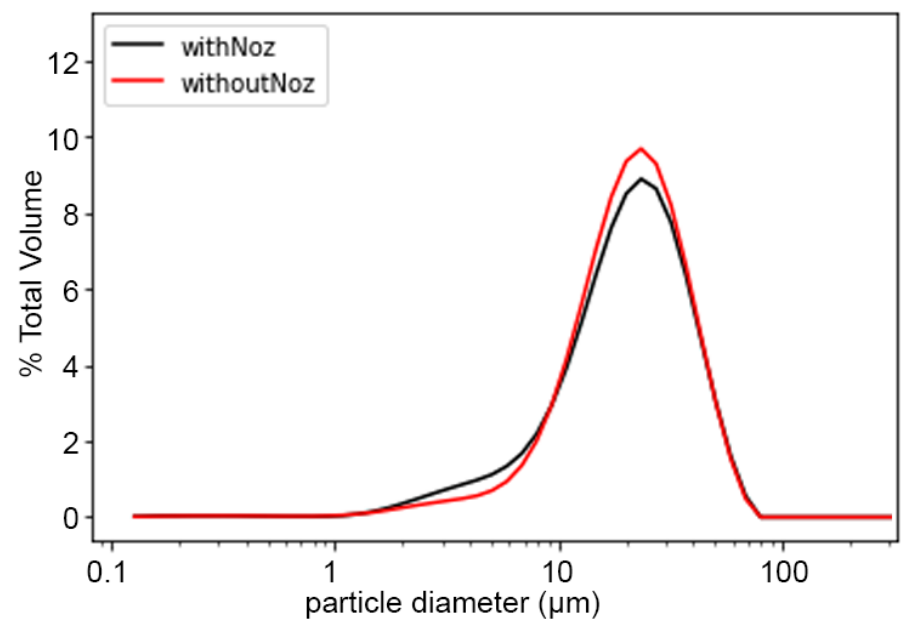

(a) Particle size distribution
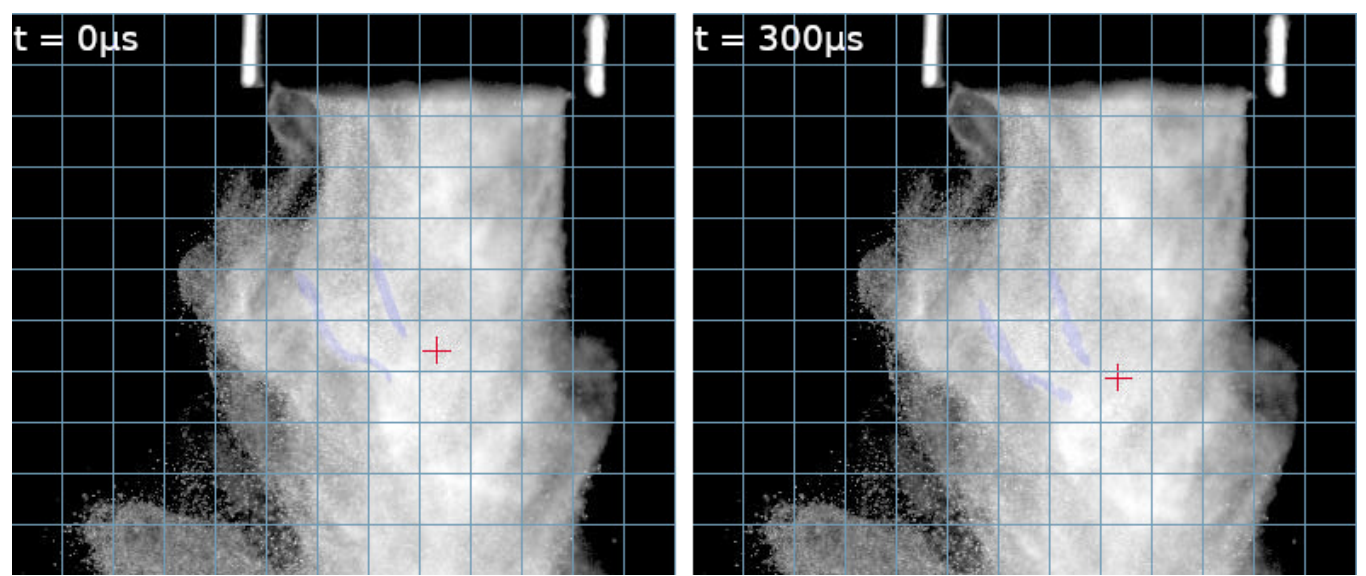

(b) Detection of particle velocity

Fig. 4. Nebuliser spray charactersiation including (a) particle size distribution by volume for the nebulizer with an attached 6nozzle (labelled 'withNoz'), and without any attachment (labelled 'withoutNoz'). (b) High speed imaging of the spray showing the progression of the spray.

At the higher flow rates of 10 and $15 \mathrm{~L} \mathrm{~min}^{-1}$, there was more deposition in the right chamber for particles greater than $24 \mu \mathrm{m}$.

In the Post-Op model total deposition efficiency was similar to the Pre-Op model, but the distribution across the regions was different. In particular, there was increased deposition in the left and right nasal cavities of up to $10 \%$ predominantly for $14-30 \mu \mathrm{m}$ particles (shown in the net change image of Fig. 5), while in the sinuses, increased deposition of up to 3\% was found for 4$20 \mu \mathrm{m}$ particles. The latter was more evident in the left nasal cavity, and at lower flow rates.

\subsection{Particle Deposition Distribution}

Particle deposition distribution in the Post-Op model was analysed for the three inhalation flow rates (Fig. 5). Larger particles were deposited on the superior nasal walls and the nasal valve region primarily due to high particle inertia. Large particles were found on the floor of the nasal cavity for $5 \mathrm{~L} \mathrm{~min}^{-1}$ inhalation due to gravitational sedimentation but were absent for $15 \mathrm{~L} \mathrm{~min}^{-1}$. Sinus deposition in the left chamber was primarily found in the maxillary, ethmoid, and frontal sinuses, while in the right chamber was mostly found in the maxillary, ethmoid, and sphenoid sinuses. For both chambers, the amount of sinus deposition diminished with increasing flow rate.

\subsection{Identifying Particle Locations of Sinus Deposition}

A cross-sectional plane was created near the nasal valve region (see Fig. 7), and reverse particle tracking was performed for every particle that deposited within a sinus. The location of each 

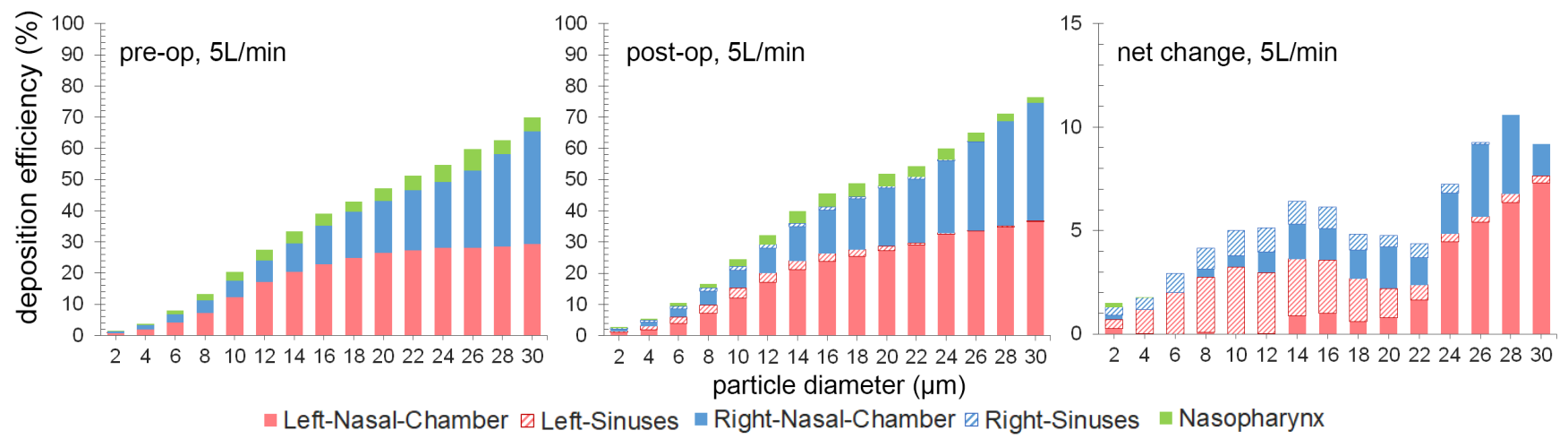

(a) Deposition efficiency for flow rate of $5 \mathrm{~L} \mathrm{~min}{ }^{-1}$
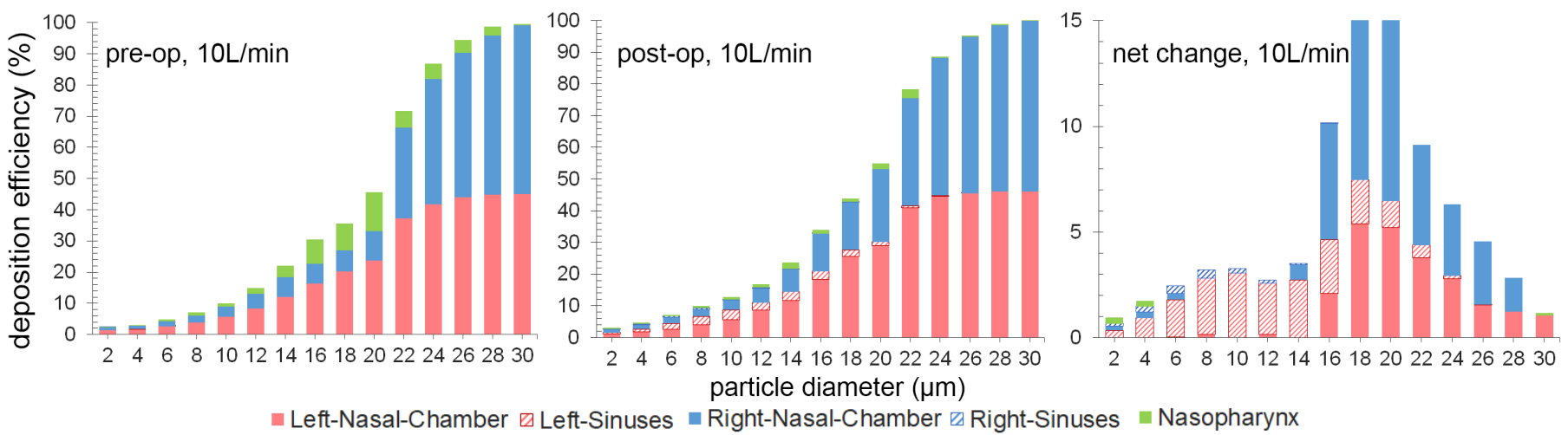

(b) Deposition efficiency for flow rate of $10 \mathrm{~L} \mathrm{~min}^{-1}$
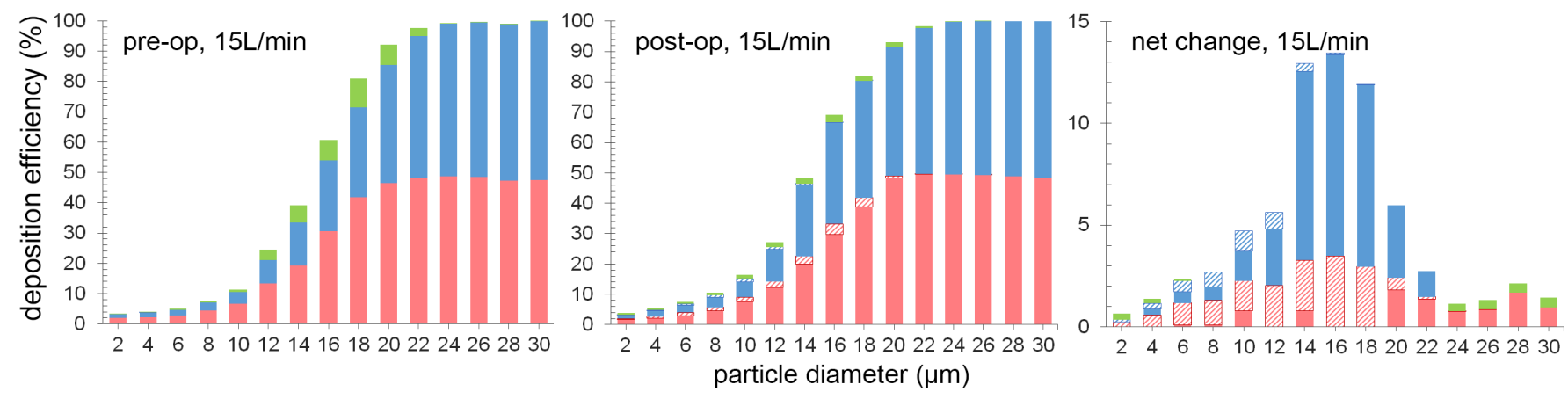

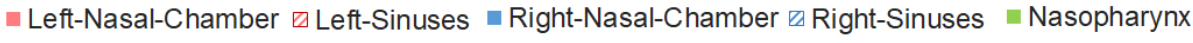

(c) Deposition efficiency for flow rate of $15 \mathrm{~L} \mathrm{~min}^{-1}$

Fig. 5. Deposition efficiency in the Pre-op and Post-op models for individual particle sizes from $2 \mu \mathrm{m}$ to $30 \mu \mathrm{m}$ at steady inhalation rates of 5, 10, $15 \mathrm{~L} \mathrm{~min}^{-1}$. The 'net change' sub-figure represents deposition change due to surgery (i.e., post-op deposition minus pre-op deposition).

sinus-deposited particle passing through the nasal valve plane was identified by its spatial location ( $x, y, z$ positions) and mapped onto the diagram shown in Fig. $7(b)$, colored by particle size and Fig. 7(c) colored by deposition region. The results suggest that, in order to reach the sinuses, particles introduced into the nasal entrance need to be in the superior half of the plane. Larger particles $(>20 \mu \mathrm{m})$ were only found to reach the sinuses for a flow rate of $5 \mathrm{~L} \mathrm{~min}^{-1}$, while particles $<16 \mu \mathrm{m}$ were able to reach the sinuses for all flow rates.

\subsection{Drug Delivery Targeting Maxillary Sinus Deposition}

To evaluate the effectiveness of this technique for targeted drug delivery, an injection of particles directed towards the superior half of the nasal valve plane (based on the results of Fig. 7) was performed. The thin, vertical plane of the nasal valve was extracted through a plane slice in 


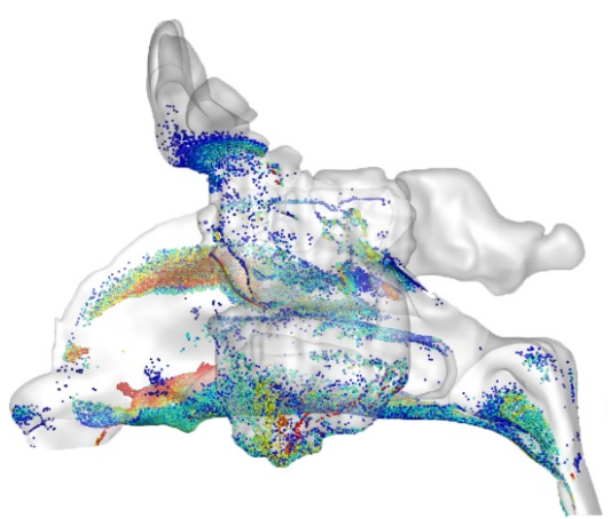

$5 \mathrm{~L} \mathrm{~min}^{-1}$

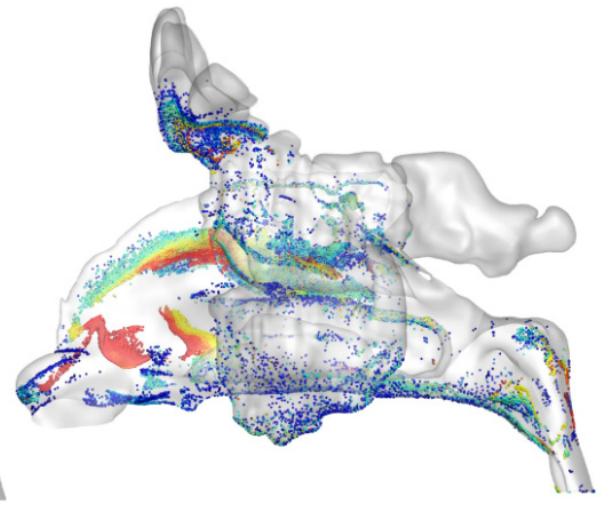

$10 \mathrm{~L} \mathrm{~min}^{-1}$

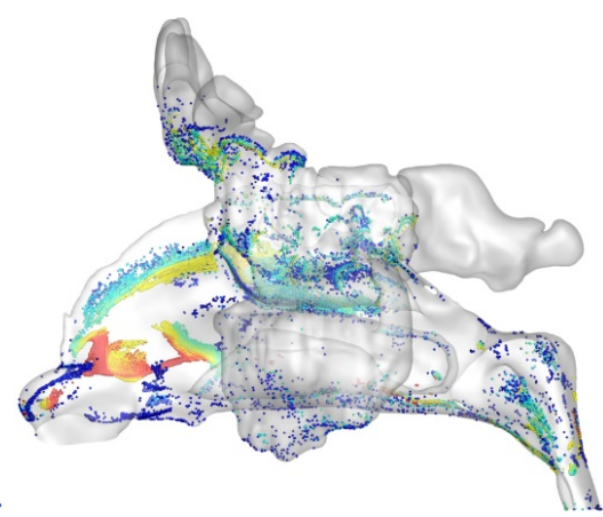

$15 \mathrm{~L} \mathrm{~min}^{-1}$

(a) Deposition in Post-op model Left Chamber

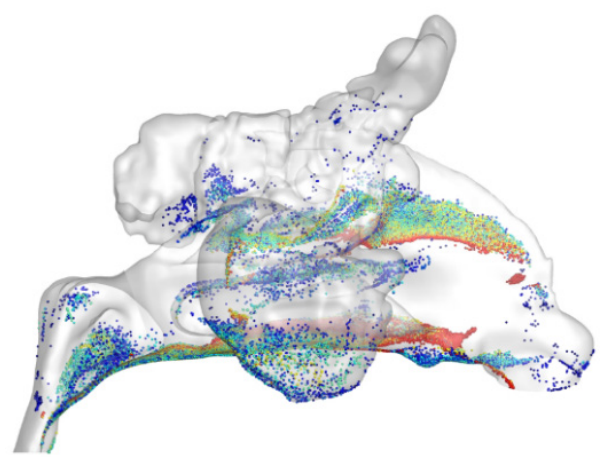

$5 \mathrm{~L} \mathrm{~min}^{-1}$

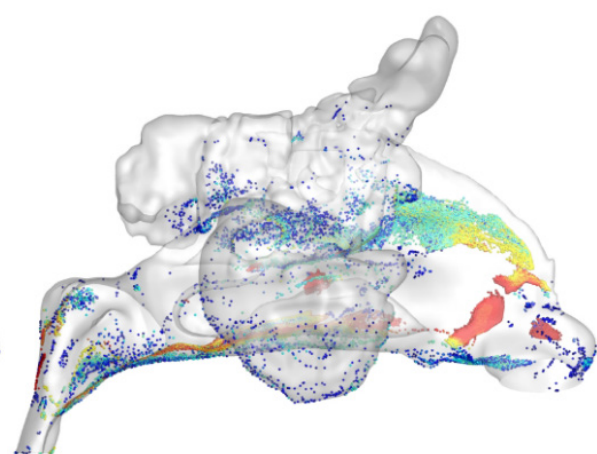

$10 \mathrm{~L} \mathrm{~min}^{-1}$

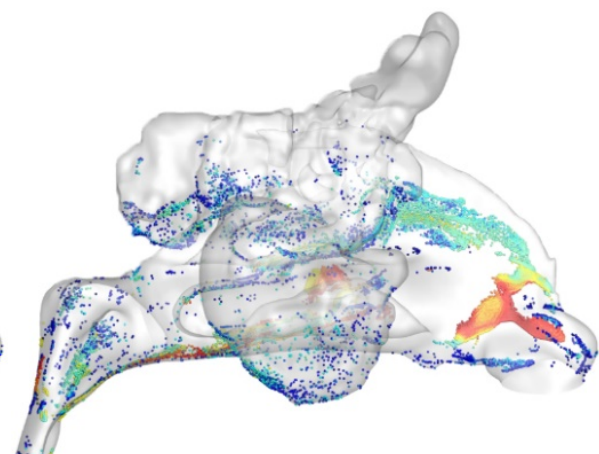

$15 \mathrm{~L} \mathrm{~min}^{-1}$

$\begin{array}{lllllllllllllll}2 & 4 & 6 & 8 & 10 & 12 & 14 & 16 & 18 & 20 & 22 & 24 & 26 & 28 & 30\end{array}$ particle size (microns)

(b) Deposition in Post-op model Right Chamber

Fig. 6. Particle deposition distribution in the (a) left chamber and (b) right chamber of the Post-op model for each flow rate. Deposited particles were colored by particle size.

Fluent that outputted the coordinates. The superior half of the nasal valve plane shape resembled a thin ellipsoid pattern. Fig. 8(a) shows the particles introduced from a single location with an ellipsoidal spray cone with a width of $1 \mathrm{~mm}$, height of $3 \mathrm{~mm}$, and thickness of $1 \mathrm{~mm}$ (Fig. 8(a)). As a reference, the orientation angles at the $0.5 \mathrm{~mm}, 1.5 \mathrm{~mm}$, and $2.5 \mathrm{~mm}$ of the ellipsoid were $63.4^{\circ}, 69.4^{\circ}$, and $76.0^{\circ}$ in the anterior-posterior axis $\left(0^{\circ}=\right.$ horizontal and $90^{\circ}=$ vertical $)$; while the lateral direction was kept constant at $78.7^{\circ}$ to the septum wall, $\left(0^{\circ}=\right.$ horizontal $/$ perpendicular to the septum and $90^{\circ}=$ vertical/parallel with the septum). This arrangement was chosen as it most accurately represented the particle pattern identified while still conforming to the insertion characteristics of a handheld spray device. Atomised droplets from a nasal spray device showed velocities of up to $20 \mathrm{~m} \mathrm{~s}^{-1}$ (Inthavong et al., 2015). For this study, two spray particle velocities were used, $5 \mathrm{~m} \mathrm{~s}^{-1}$ and $15 \mathrm{~m} \mathrm{~s}^{-1}$. An inhalational flow rate of $5 \mathrm{~L} \mathrm{~min}^{-1}$ was used since the problematic issue of high particle inertia leads to early impaction onto the anterior nasal cavity region.

Particle trajectories for representative particles of $10,14,18$, and $22 \mu \mathrm{m}$ showed the initial particle velocity of $5 \mathrm{~m} \mathrm{~s}^{-1}$ (red coloured stream) dissipates within a short distance and becomes entrained in the inhaled flow stream (Fig. 8(b)). The particles reach the middle turbinates before turning at the surgically altered ostia and entering the maxillary sinus. Some particles continue the circular trajectory inside the sinus before exiting out of the sinus and re-entering the main nasal passage, before finally exiting through the nasopharynx.

The deposition efficiency increased remarkably from a maximum of $3 \%$ for the naturally inhaled particle depositions to a maximum of 55\% for targeted delivery using $22 \mu \mathrm{m}$ particles. The deposition patterns within the maxillary sinus showed posterior wall deposition for all particles, and additional inferior floor deposition for 14, 18, and $22 \mu \mathrm{m}$. 


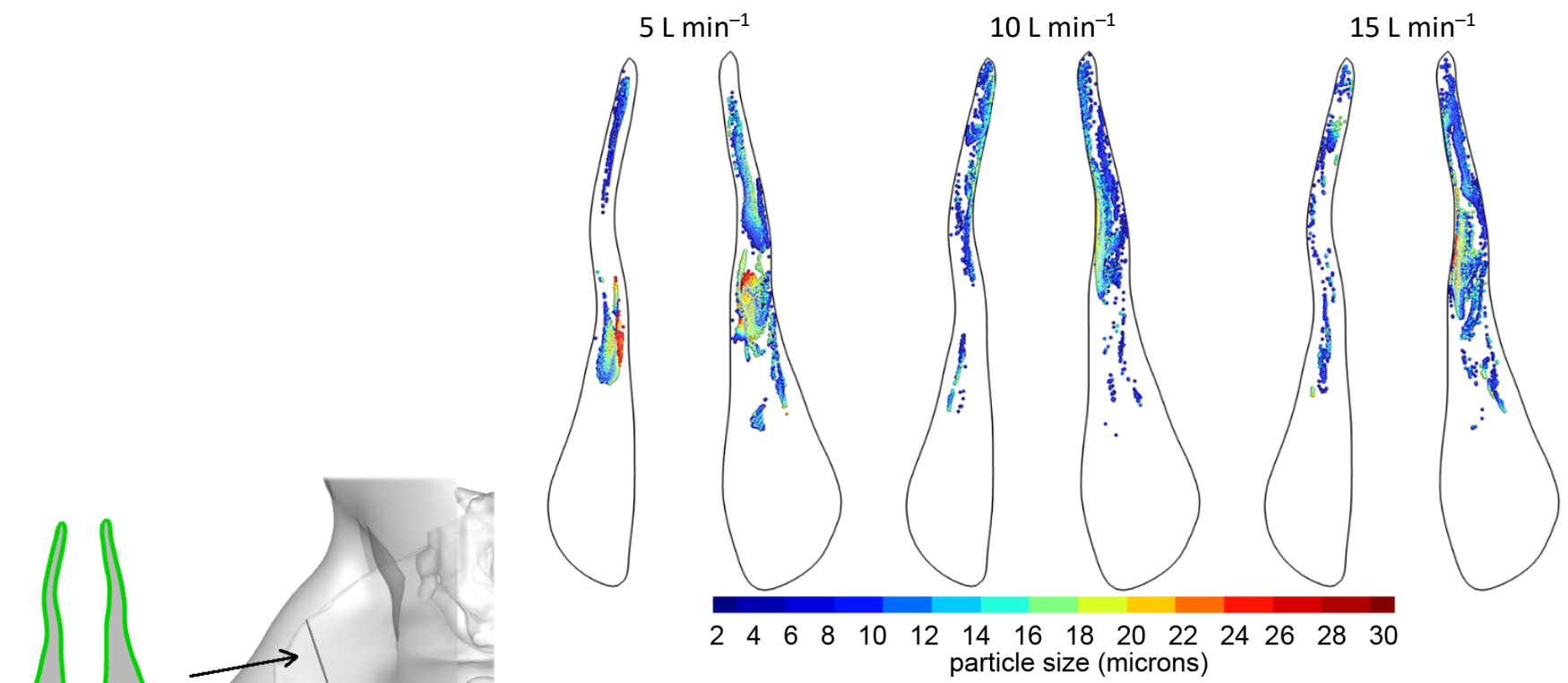

(b) particles colored by size

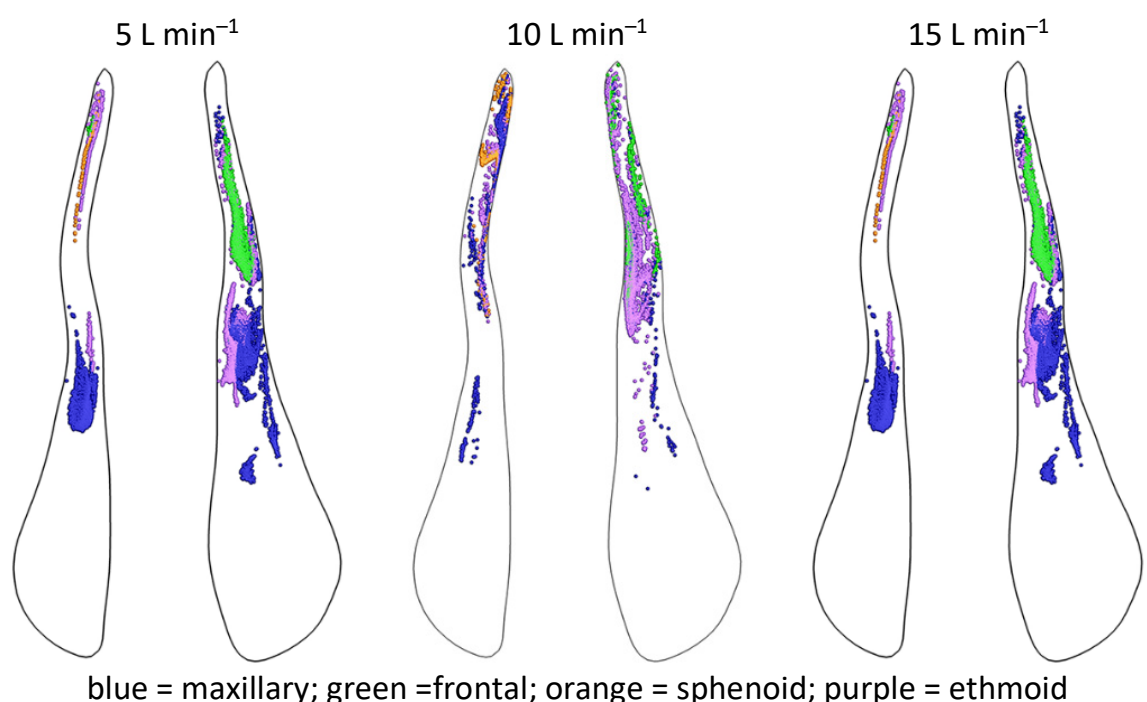

(c) particles colored by deposited region

Fig. 7. Reverse-tracked locations of particles that pass through (a) a plane near the nasal valve entrance, that eventually deposit in the sinuses. The particles passing through the plane were colored by (b) particle diameter, and (c) deposited regions.

For many commercial nasal sprays, the initial particle velocity is closer to $15 \mathrm{~m} \mathrm{~s}^{-1}$ which was used in Fig. 9. The initially high particle velocity was evident by the linear paths coloured by red particle trajectories (Fig. 9(a)), which persisted longer (higher inertia for larger particles). Maxillary sinus deposition for 10 and $14 \mu \mathrm{m}$ was greater while for 18 and $22 \mu \mathrm{m}$ was less, when compared to the previous case for initial particle velocity of $5 \mathrm{~m} \mathrm{~s}^{-1}$. The deposition patterns showed more significant deposition in the inferior region of the maxillary sinus, while there was posterior maxillary deposition for 10,14 , and $18 \mu \mathrm{m}$ but not for $22 \mu \mathrm{m}$ particles.

\subsection{Maxillary Sinus Deposition Fractions with Targeted Drug Delivery}

The deposition variation with respect to particle diameter (Fig. 10) showed an increase in maxillary sinus deposition, reaching a peak before decreasing, while the total deposition in all regions increased with increased particle size. This resulted in a similar trend for the sinus to total deposition fraction. High peak values close to $100 \%$ suggest all deposited particles were attributed to the maxillary sinus and nowhere else. Peak maxillary sinus deposition was $63 \%$ for $20 \mu \mathrm{m}$ at $5 \mathrm{~m} \mathrm{~s}^{-1}$ particle injection and $39 \%$ for $14 \mu \mathrm{m}$ at $15 \mathrm{~m} \mathrm{~s}^{-1}$ particle injection. 

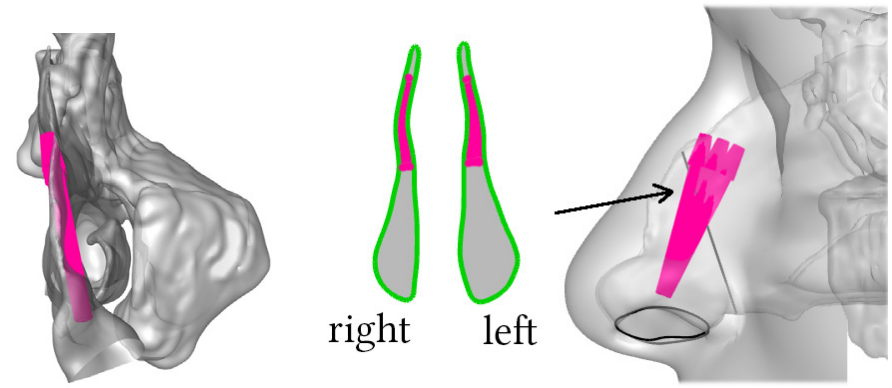

(a) Targeted nasal drug delivery release locations

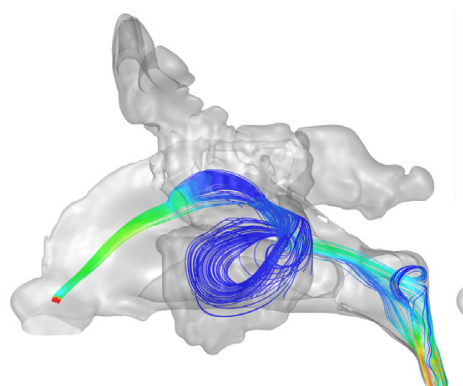

$10 \mu \mathrm{m}$ (9\% deposition)

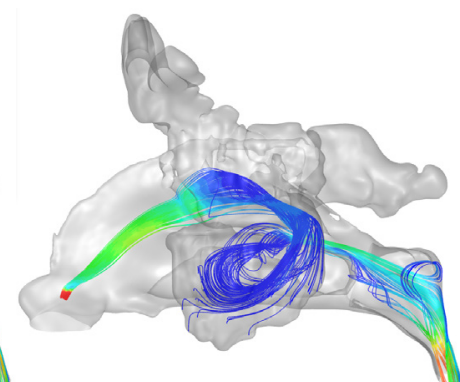

$14 \mu \mathrm{m}$ (28\% deposition)

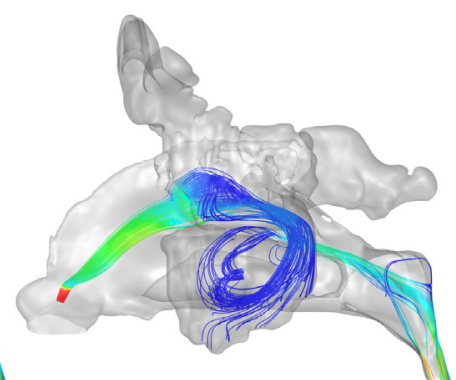

$18 \mu \mathrm{m}$ (52\% deposition)

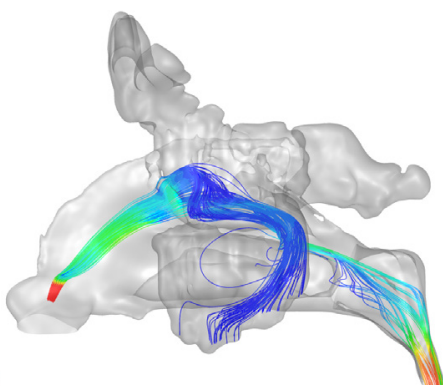

$22 \mu \mathrm{m}$ (55\% deposition)

(b) particle trajectories released at $5 \mathrm{~m} \mathrm{~s}^{-1}$, with inhalation rate of $5 \mathrm{~L} \mathrm{~min}^{-1}$

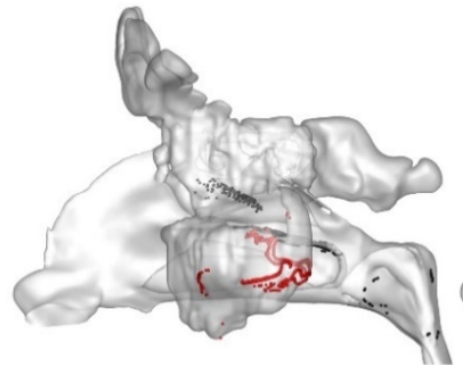

$10 \mu \mathrm{m}$ (9\% deposition)

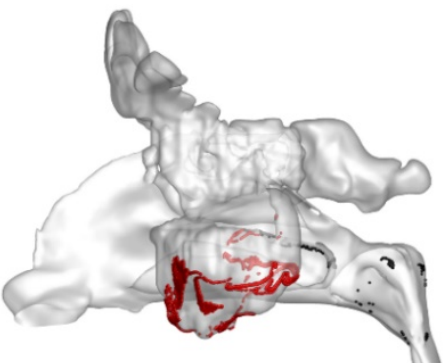

$14 \mu \mathrm{m}$ (28\% deposition)

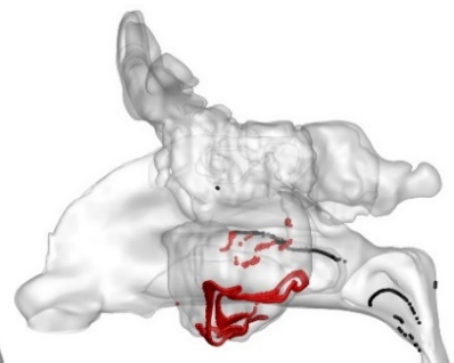

$18 \mu \mathrm{m}$ (52\% deposition)

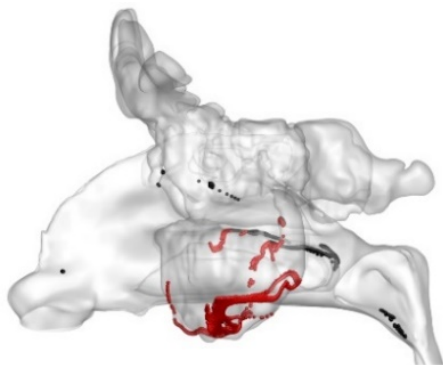

$22 \mu \mathrm{m}$ (55\% deposition)

(c) particle deposition distribution at $5 \mathrm{~m} \mathrm{~s}^{-1}$, with inhalation rate of $5 \mathrm{~L} \mathrm{~min}^{-1}$

Fig. 8. (a) Nasal drug delivery release orientation into the main nasal passage targeting the maxillary sinuses; (b) particle trajectories of $10,14,18$, and $22 \mu \mathrm{m}$, released at $5 \mathrm{~m} \mathrm{~s}^{-1}$. Trajectory lines coloured by velocity magnitude (capped at $1.5 \mathrm{~m} \mathrm{~s}$ ), and its deposition efficiency in the maxillary sinus is given; $(c)$ deposition distribution coloured by location, red = maxillary; black = all other deposited regions.

\section{DISCUSSION}

Several nasal spray devices with varying nozzle designs are available for patient use. However, there is little evidence to differentiate one design from another. This study provided objective insights into the behaviour of particles that could be delivered from a nebuliser as an alternative to nasal sprays. From the different combinations of parameters, at least in this patient model, the optimal size, and speed of particles, combined with optimised targeted initial positions at a gentle inhalational flow rate of $5 \mathrm{~L} \mathrm{~min}^{-1}$ can significantly enhance targeted maxillary sinus deposition.

The main finding of this study is that the movement of particles depends on inertia, and that maxillary sinus deposition requires these particles to be aimed superiorly within the nasal valve region, to then slow down superiorly in the nasal cavity and deposit via sedimentation.

Very small particles, when directed into the nose, follow the airflow through to the nasopharyngeal outlet, bypassing the sinonasal cavities, or circling within the maxillary sinus and back out through the ostium. On the other hand, larger particles that were able to reach the middle turbinate were then able to be carried by inhaled air further into the upper nasal cavity. From there, 


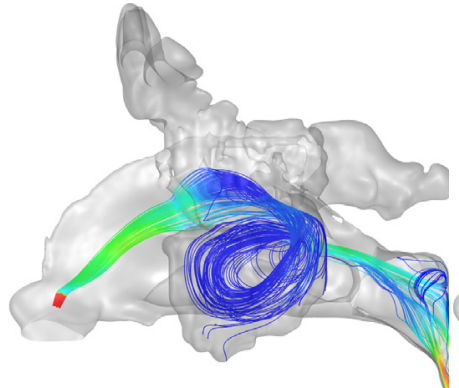

$10 \mu \mathrm{m}$ (16\% deposition)

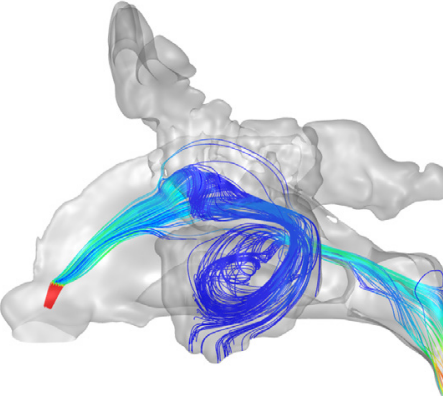

$14 \mu \mathrm{m}$ (39\% deposition)

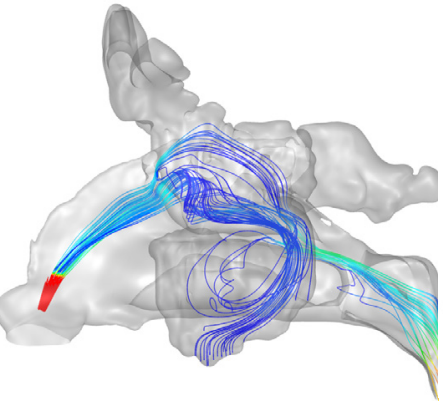

$18 \mu \mathrm{m}$ (19\% deposition)

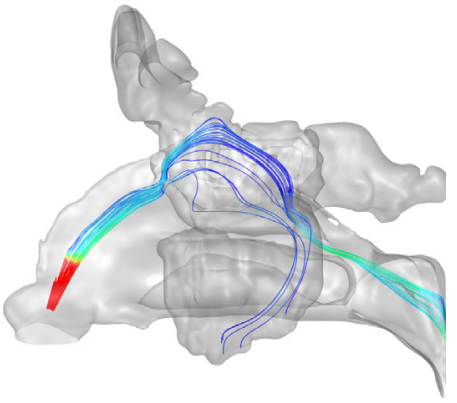

$22 \mu \mathrm{m}$ (5\% deposition)

(a) particle trajectories released at $15 \mathrm{~m} \mathrm{~s}^{-1}$, with inhalation rate of $5 \mathrm{~L} \mathrm{~min}^{-1}$

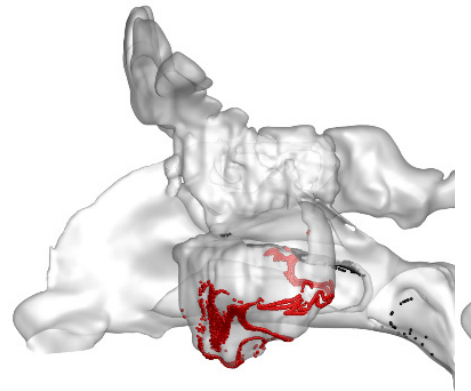

$10 \mu \mathrm{m}$ (16\% deposition)

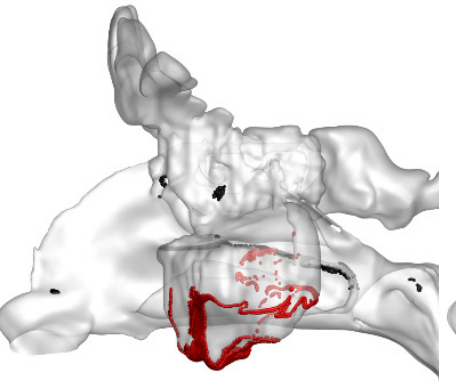

$14 \mu \mathrm{m}$ (39\% deposition)

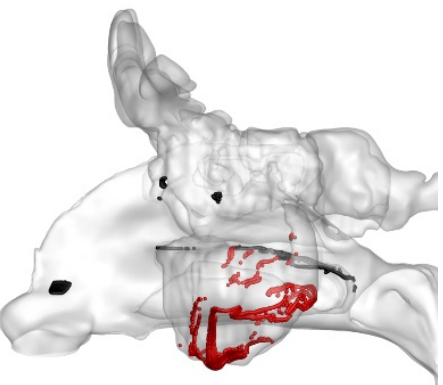

$18 \mu \mathrm{m}$ (19\% deposition)

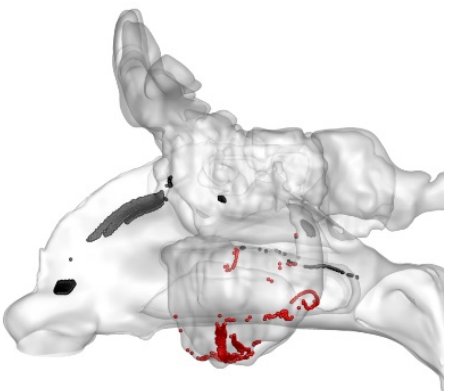

$22 \mu \mathrm{m}$ (5\% deposition)

(b) particle deposition distribution at $15 \mathrm{~m} \mathrm{~s}^{-1}$, with inhalation rate of $5 \mathrm{~L} \mathrm{~min}^{-1}$

Fig. 9. (a) Particle trajectories of 10,14,18, and $22 \mu \mathrm{m}$, released at $15 \mathrm{~m} \mathrm{~s}^{-1}$. Trajectory lines coloured by velocity magnitude (capped at $1.5 \mathrm{~m} \mathrm{~s}^{-1}$ ), and its deposition efficiency in the maxillary sinus is given; (b) deposition distribution coloured by location, red = maxillary; black = all other deposited regions.

sedimentation of these particles would then allow final deposition into the various sinuses. This challenges a long-standing mantra in surgical practice that the optimal spray technique for delivery to the sinuses should have the nozzle aimed posterolaterally (although the postero-lateral recommendation is generally based on non-operated patients with allergic rhinitis). This suggests that nasal sprays intended for the maxillary sinuses may be better aimed superiorly under gentle breathing (inspiration) conditions.

Additionally, to reach the maxillary sinus, the posterior maxillary wall and the posterior margin of the maxillary ostium were significant structures in this model that facilitated sinus deposition, evident from the particle trajectories (Figs. 8(b) and 9(a)). This suggests that if one of the aims of surgery is to facilitate the use of post-operative topical spray medications, a critical area that needs to be addressed in maxillary sinus surgery is the posterior fontanelle.

Ultimately, the optimal nasal spray will, of course, still depend on its intended use. That is, the most effective particle size, spray velocity, spray trajectory and breathing condition will depend upon the location of the nasal cavity or sinus mucosa that needs to be addressed. Fig. 10 demonstrates the relationship between particle diameter and deposition for spray velocities of $5 \mathrm{~m} \mathrm{~s}^{-1}$ and $15 \mathrm{~m} \mathrm{~s}^{-1}$. The blue lines represent particle deposition in the maxillary sinus, while the orange lines demonstrate total deposition within the sino-nasal cavity (all regions of the nose and sinuses, as opposed to deposition at the nasopharynx or outflow without deposition).

Typically, a combination of both nasal cavity and sinuses is desired. A higher total deposition into the nasal cavity would mean that less medication is "wasted" into the lower airway, while effective sinus deposition is self-explanatory. Therefore, it appears that particles of approximately 20 microns at a spray velocity of $5 \mathrm{~m} \mathrm{~s}^{-1}$ and an inhalation velocity of $5 \mathrm{~L} \mathrm{~min}^{-1}$ seem to demonstrate acceptable deposition at both sites in this model. From this baseline, increasing the particle size slightly may tend more toward nasal cavity deposition, perhaps more helpful in patients where rhinitis is the predominant phenotype. Wofford et al. (2015) demonstrated that maxillary sinus 


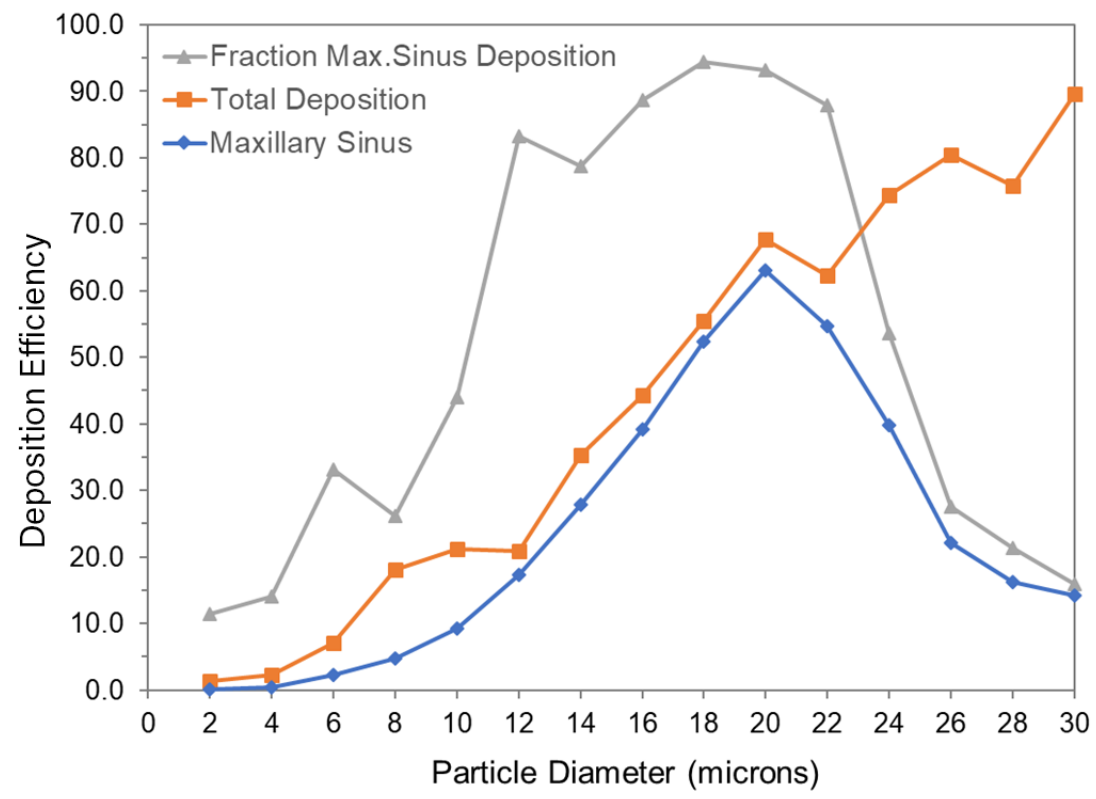

(a) Deposition for particles with injection velocity of $5 \mathrm{~m} \mathrm{~s}^{-1}$

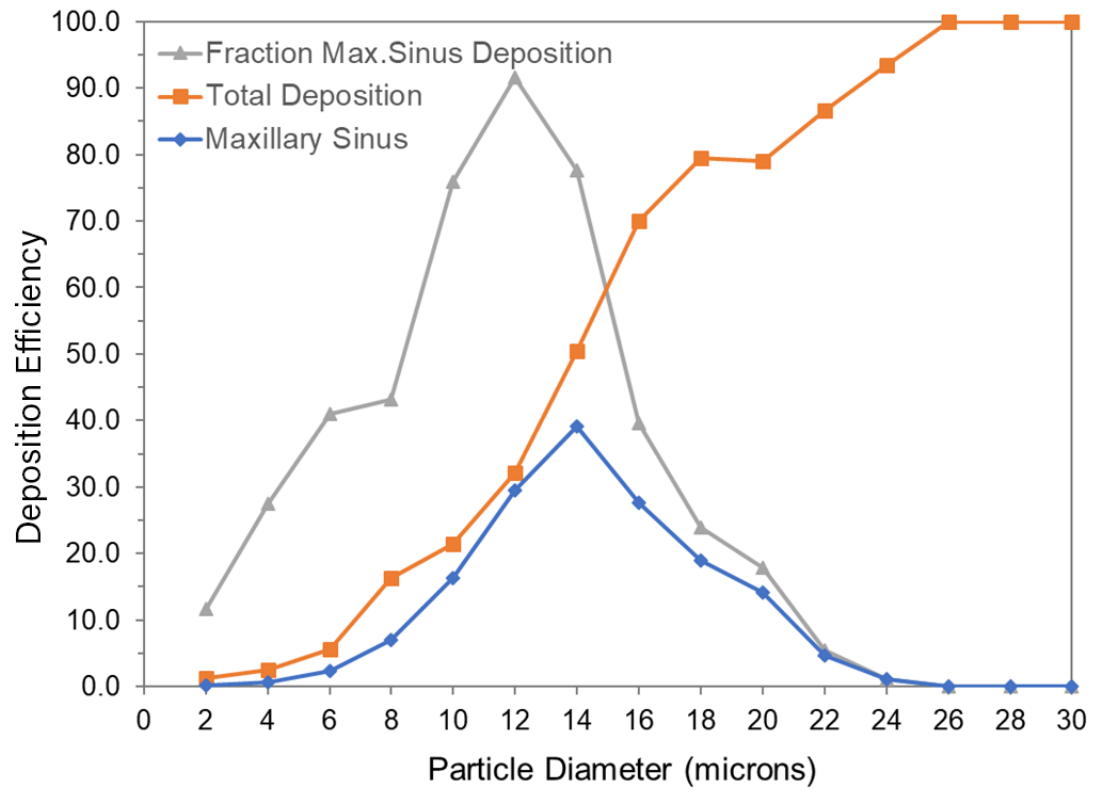

(b) Deposition for particles with injection velocity of $15 \mathrm{~m} \mathrm{~s}^{-1}$

Fig. 10. Deposition profiles for (a) initial particle velocity of $5 \mathrm{~m} \mathrm{~s}^{-1}$; and (b) initial particle velocity of $15 \mathrm{~m} \mathrm{~s}^{-1}$. The blue line represents deposition in the maxillary sinus, orange line is total deposition within all regions, and grey is the proportion or fraction of maxillary sinus to total deposition.

ventilation and drug delivery increased following FESS, where particles within a 5-20 $\mu \mathrm{m}$ size range led to peak maxillary sinus deposition for sprayed particles, while Chen et al. (2012) found approximately $10 \mu \mathrm{m}$ particles should improve intranasal medication deposition into the maxillary sinus cavity following FESS.

Several limitations exist with this proof-of-concept study. Firstly, the results of this study are based on only a single patient model, and findings may differ in other anatomical configurations or surgical states. Naturally, future studies examining multiple patient models with different anatomical features and incorporating several physiological features such as the nasal cycle will be explored in subsequent studies. The deposition values were under a steady-state flow, and while this is relevant for a short space of time found in nasal spray application ( $<2$ secs of inhalation), 
a cyclic inhalation may provide variation in the results. Furthermore, atomised spray particles are produced with high momentum and wide spray plumes. In contrast, the results had relied on an optimised spray plume condition - thereby providing opportunities for new novel drug delivery devices.

In addition to multiple patient models incorporating varying anatomy and degree of surgical intervention, future studies will aim to identify the optimised characteristics for other targeted sinonasal locations and conditions, such as the frontal region following Draf III procedures or the sphenoid sinus following treatment of fungus ball. By determining the optimised set of variables using CFD techniques, confirmatory physical experiments can be performed using a significantly reduced number of parameters. Patient testing of optimised device designs may then be undertaken to provide the final validation of experimental outcomes. The results of such studies will have a significant translational impact in the ideal management of CRS and other sinonasal conditions.

\section{CONCLUSION}

A nasal cavity model underwent virtual surgery by removing the regions typically addressed in real-life sinus surgery. Particles from the external environment were introduced within the breathing region of the nose. Under steady inhalation rates of 5, 10, $15 \mathrm{~L} \mathrm{~min}^{-1}$, the particles, initially at rest, were inhaled and their deposition recorded. Using a reverse particle-tracking technique, optimised spray entry locations were determined, which targeted the superior half of the nasal valve plane. The spray particles need to be directed within a narrow ellipsoidal column to match the nasal valve plane. If this could be achieved, a remarkable $55 \%$ deposition efficiency into the maxillary sinus could be achieved. The mechanism for increased deposition was locating the optimised entry position that allowed the particles to be transported by the inhaled airflow into the maxillary sinuses. A low shallow inhalational flow of $5 \mathrm{~L} \mathrm{~min} \mathrm{mith}^{-1}$ winjected $20 \mu \mathrm{m}$ particles at $5 \mathrm{~m} \mathrm{~s}^{-1}$ was ideal. This proof-of-concept single patient study provides the basis for future research incorporating multiple patient models with varying anatomy to optimise spray devices and techniques to target specific post-operative sinonasal locations and improve the management of CRS other mucosal conditions.

\section{ACKNOWLEDGEMENTS}

The authors gratefully acknowledge the financial support provided by Garnett Passe and Rodney Williams Memorial Foundation Conjoint Grant 2019 (Inthavong-Singh).

\section{DISCLAIMER}

A/Prof Kiao Inthavong and A/Prof Narinder Singh are consultants for Optinose Inc., Pennsylvania, United States.

\section{SUPPLEMENTARY MATERIAL}

Supplementary material for this article can be found in the online version at https://doi. org/10.4209/aaqr.210098

\section{REFERENCES}

Chen, W.H., Chang, C.M., Mutuku, J.K., Lam, S.S., Lee, W.J. (2021). Aerosol deposition and airflow dynamics in healthy and asthmatic human airways during inhalation. J. Hazard. Mater. 416, 125856. https://doi.org/10.1016/j.jhazmat.2021.125856

Chen, X.B., Lee, H.P., Chong, V.F., Wang, D.Y. (2012). Drug delivery in the nasal cavity after functional endoscopic sinus surgery: a computational fluid dynamics study. J. Laryngol. Otol. 
126, 487-494. https://doi.org/10.1017/s0022215112000205

Chen, X.B., Lee, H.P., Chong, V.F.H., Wang, D.Y. (2010). A computational fluid dynamics model for drug delivery in a nasal cavity with inferior turbinate hypertrophy. J. Aerosol Med. Pulm. Drug Delivery 23, 329-338. https://doi.org/10.1089/jamp.2009.0776

Cheng, Y.S., Holmes, T.D., Gao, J., Guilmette, R.A., Li, S., Surakitbanharn, Y., Rowlings, C. (2001). Characterization of nasal spray pumps and deposition pattern in a replica of the human nasal airway. J. Aerosol Med. 14, 267-280. https://doi.org/10.1089/08942680152484199

Chung, J.C. (2006). Redirecting the growth pattern with rapid maxillary expander and chin cup treatment: Changing breathing pattern from oral to nasal. World J. Orthod. 7, 236-253.

Dayal, P., Shaik, M.S., Singh, M. (2004). Evaluation of different parameters that affect dropletsize distribution from nasal sprays using the malvern spraytec. J. Pharm. Sci. 93, 1725-1742. https://doi.org/10.1002/jps.20090

Djupesland, P.G., Messina, J.C., Palmer, J.N. (2019). Deposition of drugs in the nose and sinuses with an exhalation delivery system vs conventional nasal spray or high-volume irrigation in Draf II/III post-surgical anatomy. Rhinology 58, 175-183. https://doi.org/10.4193/Rhin18.304

Djupesland, P.G., Skretting, A. (2012). Nasal deposition and clearance in man: Comparison of a bidirectional powder device and a traditional liquid spray pump. J. Aerosol Med. Pulm. Drug Delivery 25, 280-289. https://doi.org/10.1089/jamp.2011.0924

Djupesland, P.G., Skretting, A., Winderen, M., Holand, T. (2004). Bi-directional nasal delivery of aerosols can prevent lung deposition. J. Aerosol Med. 17, 249-259. https://doi.org/10.1089/ja m.2004.17.249

Dong, J., Shang, Y., Inthavong, K., Chan, H.K., Tu, J. (2018). Partitioning of dispersed nanoparticles in a realistic nasal passage for targeted drug delivery. Int. J. Pharm. 543, 83-95. https://doi.org/ 10.1016/j.ijpharm.2018.03.046

Fedorov, A., Beichel, R., Kalpathy-Cramer, J., Finet, J., Fillion-Robin, J.C., Pujol, S., Bauer, C., Jennings, D., Fennessy, F., Sonka, M., Buatti, J., Aylward, S., Miller, J.V., Pieper, S., Kikinis, R. (2012). 3D Slicer as an image computing platform for the Quantitative Imaging Network. Magn. Reson. Imaging 30, 1323-1341. https://doi.org/10.1016/j.mri.2012.05.001

Frank, D.O., Kimbell, J.S., Pawar, S., Rhee, J.S. (2012). Effects of anatomy and particle size on nasal sprays and nebulizers. Otolaryngol. Head Neck Surg. 146, 313-319. https://doi.org/10.1177/0 194599811427519

Fung, M.C., Inthavong, K., Yang, W., Lappas, P., Tu, J. (2013). External characteristics of unsteady spray atomization from a nasal spray device. J. Pharm. Sci. 102, 1024-1035. https://doi.org/10. 1002/jps.23449

Inthavong, K., Ge, Q., Se, C.M., Yang, W., Tu, J. (2011). Simulation of sprayed particle deposition in a human nasal cavity including a nasal spray device. J. Aerosol Sci. 42, 100-113. https://doi.org/ 10.1016/j.jaerosci.2010.11.008

Inthavong, K., Ge, Q.J., Li, X.D., Tu, J.Y. (2012). Detailed predictions of particle aspiration affected by respiratory inhalation and airflow. Atmos. Environ. 62, 107-117. https://doi.org/10.1016/j. atmosenv.2012.07.071

Inthavong, K., Ge, Q.J., Li, A., Tu, J.Y. (2013). Source and trajectories of inhaled particles from a surrounding environment and its deposition in the respiratory airway. Inhalation Toxicol. 25, 280-291. https://doi.org/10.3109/08958378.2013.781250

Inthavong, K., Fung, M.C., Yang, W., Tu, J. (2015). Measurements of droplet size distribution and analysis of nasal spray atomization from different actuation pressure. J. Aerosol Med. Pulm. Drug Delivery 28, 59-67. https://doi.org/10.1089/jamp.2013.1093

Inthavong, K., Chetty, A., Shang, Y., Tu, J. (2018). Examining mesh independence for flow dynamics in the human nasal cavity. Comput. Biol. Med. 102, 40-50. https://doi.org/10.1016/j.compbio med.2018.09.010

Inthavong, K. (2020). From Indoor exposure to inhaled particle deposition: A multiphase journey of inhaled particles. Exp. Computat. Multiph. Flow 2, 59-78. https://doi.org/10.1007/s42757019-0046-6

Kimbell, J.S., Segal, R.A., Asgharian, B., Wong, B.A., Schroeter, J.D., Southall, J.P., Dickens, C.J., Brace, G., Miller, F.J. (2007). Characterization of deposition from nasal spray devices using a computational fluid dynamics model of the human nasal passages. J. Aerosol Med. 20, 59-74. https://doi.org/10.1089/jam.2007.0578 
Kleinstreuer, C., Zhang, Z., Donohue, J.F. (2008). Targeted drug-aerosol delivery in the human respiratory system. Annu. Rev. Biomed. Eng. 10, 195-220. https://doi.org/10.1146/annurev.b ioeng.10.061807.160544

Lam, K., Tan, B.K., Lavin, J.M., Meen, E., Conley, D.B. (2013). Comparison of nasal sprays and irrigations in the delivery of topical agents to the olfactory mucosa. Laryngoscope 123, 29502957. https://doi.org/10.1002/lary.24239

Lee, K.B., Jeon, Y.S., Chung, S.K., Kim, S.K. (2016). Effects of partial middle turbinectomy with varying resection volume and location on nasal functions and airflow characteristics by CFD. Comput. Biol. Med. 77, 214-221. https://doi.org/10.1016/j.compbiomed.2016.08.014

Luk, L.J., DelGaudio, J.M. (2017). Topical drug therapies for chronic rhinosinusitis. Otolaryngol. Clin. North Am. 50, 533-543. https://doi.org/10.1016/j.otc.2017.01.005

Morsi, S., Alexander, A. (1972). An investigation of particle trajectories in two-phase flow systems. J. Fluid Mech. 55, 193-208. https://doi.org/10.1017/S0022112072001806

Mutuku, J.K., Hou, W.C., Chen, W.H. (2020). An overview of experiments and numerical simulations on airflow and aerosols deposition in human airways and the role of bioaerosol motion in COVID-19 transmission. Aerosol Air Qual. Re. 20, 1172-1196. https://doi.org/10.42 09/aaqr.2020.04.0185

Saijo, R., Majima, Y., Hyo, N., Takano, H. (2004). Particle deposition of therapeutic aerosols in the nose and paranasal sinuses after transnasal sinus surgery: A cast model study. Am. J. Rhinol. 18, 1-7. https://doi.org/10.1177/194589240401800101

Sanmiguel-Rojas, E., Burgos, M.A., Esteban-Ortega, F. (2018). Nasal surgery handled by CFD tools. Int. J. Numer. Methods Biomed. Eng. 34, e3126. https://doi.org/10.1002/cnm.3126

Siu, J., Johnston, J.J., Pontre, B., Inthavong, K., Douglas, R.G. (2019). Magnetic resonance imaging evaluation of the distribution of spray and irrigation devices within the sinonasal cavities. Int. Forum Allergy Rhinol. 9, 958-970. https://doi.org/10.1002/alr.22376

Siu, J., Shrestha, K., Inthavong, K., Shang, Y., Douglas, R. (2020). Particle deposition in the paranasal sinuses following endoscopic sinus surgery. Comput. Biol. Med. 116, 103573. https://doi.org/10.1016/j.compbiomed.2019.103573

Snidvongs, K., Kalish, L., Sacks, R., Sivasubramaniam, R., Cope, D., Harvey, R.J. (2013). Sinus surgery and delivery method influence the effectiveness of topical corticosteroids for chronic rhinosinusitis: Systematic review and meta-analysis. Am. J. Rhinol. Allergy 27, 221-233. https://doi.org/10.2500/ajra.2013.27.3880

Winfried, M., Uwe, S., Peter, B., Gabriele, M., Karl, H., Otmar, S., Sven, B. (2014). Drug delivery to paranasal sinuses using pulsating aerosols. J. Aerosol Med. Pulm. Drug Delivery 27, 255-263. https://doi.org/10.1089/jamp.2013.1071

Wofford, M.R., Kimbell, J.S., Frank-Ito, D.O., Dhandha, V., McKinney, K.A., Fleischman, G.M., Ebert, C.S., Jr., Zanation, A.M., Senior, B.A. (2015). A computational study of functional endoscopic sinus surgery and maxillary sinus drug delivery. Rhinology 53, 41-48. https://doi.org/10.4193/Rhin1 3.065

Zhang, T.T., Li, H., Wang, S. (2012). Inversely tracking indoor airborne particles to locate their release sources. Atmos. Environ. 55, 328-338. https://doi.org/10.1016/j.atmosenv.2012.03.066 